\title{
AOA initiatives in research
}

DAVID W. RIVERS, Ph.D.

Chicago, Illinois
During the last year, the AOA Bureau of Research has embarked on a revitalized research mission. This mission is directed toward two major goals. The first goal is the targeting of AOA resources toward research areas of high priority to the osteopathic medical profession. The scientific examination of osteopathic medical philosophy and practice through basic science and clinical research is the focus of this effort. The second major goal consists of the recruitment, training, and career development of D.O.s as clinical investigators. The profession must provide opportunities for a clinical research experience for young physicians. This experience should be one that encourages and facilitiates the pursuit of a career in research.

To achieve the goal of producing research that benefits the osteopathic medical profession requires a substantial investment. It needs the efforts and cooperation of the AOA, its specialty colleges and other affiliated organizations, colleges of osteopathic medicine, osteopathic hospitals, and each and every D.O. A substantial investment in time, resources, dollars, and manpower has already been made by many, but much more is needed. As a result, the AOA has dedicated a significant portion of its resources to the enhancement of its research effort. New committees have been established to address three areas: research grants, research funding, and the research conference. Many individuals have volunteered their time and expertise to serve on these committees. A concerted effort has been made to involve representatives of many organizations that have an interest in the research efforts of the AOA. Representatives currently serving come from osteopathic medical colleges and hospitals, specialty colleges, the federal government, foundations, and industry. Also, relationships have been established with organizations such as the Centers for Disease Control, the National Institutes of Health, and the Surgeon General's office. The AOA periodically receives advice on pertinent matters from these groups and likewise has been called upon to furnish advice, consultation, and representation. Continued cooperation with agencies outside the AOA should greatly enhance the quality and impact of the Bureau's programs.

The Bureau of Research and its committees are in the process of drafting and implementing plans to achieve the identified goals. These approaches can be summarized here.

\section{Targeted research}

The targeting of research toward areas of high priority to the profession is being achieved in two ways. The first is through special projects. For example, the Bureau has launched what is reported to be the first multisite, controlled clinical trial on osteopathic manipulative treatment (OMT). The research will study somatic dysfunction of the low back by comparing patients who receive standard medical care for back pain with those who receive both standard care and OMT on several outcome measures. (The August 1987 issue of THE D.O. provides an overview of the study design process.) The research will begin at several clinical sites in early 1988.

The second way that the Bureau is targeting its resources is through the AOA research grant program. The recently announced "Request for Proposals" (RFP) calls for investigators to "apply for funds to support research that has demonstrable relevance to osteopathic theory and practice. It is the applicant's responsibility to demonstrate that relevance." The Bureau has requested the cooperation and involvement of basic scientists and clinicians to address the many unanswered questions that underlie the philosophy of osteopathic medicine. The interest of all D.O.s is sought in this endeavor. It is imperative that practicing physicians and research investigators come together. There is much to be learned from one another and much to be gained. The Bureau invites D.O.s to submit their thoughts concerning the research needs of the osteopathic medical profession.

\section{Development of clinical investigators}

The second major goal of the Bureau-the recruitment, training, and career development of clinical investigators-is being approached in several ways. In 1984, the Ad Hoc Committee on Research was charged with exploring the expansion of research opportunities in osteopathic medical education and training programs. The committee recognized that the key to developing clinical investigators is through the establishment of postdoctoral training programs having research experience as an integral component. The recommenda- 
tions of the committee were adopted by the AOA Board of Trustees, which then directed the Committee on Postdoctoral Training to request the AOA specialty colleges to develop a research component as an integral part of their training standards. Each specialty college was to reevaluate its basic standards and model program documents. Furthermore, the Board directed that, when research is a major component of a residency program, consideration be given to extending the duration of the program to incorporate all specialty training requirements plus extensive research activity. This would mean extension of residency training beyond the currently established periods.

The Ad Hoc Committee on Research made one additional recommendation that was adopted by the Board. The AOA is to provide for the development of traditional fellowship programs for subspecialty training with an emphasis on research. This policy will establish a category of research subspecialty training approval currently not available to AOA members. Such programs will be required to meet all $\mathrm{AOA}$ training requirements for that specialty.

The Bureau of Research is developing guidelines for a program that will help establish research initiatives by postdoctoral training programs. The Bureau proposes to introduce a fellowship program to help identify, educate, and train osteopathic physicians as research investigators. This effort will focus primarily on the development of clinical research opportunities in osteopathic postdoctoral training programs. An endowed funding base will be sought to support the plan.

Such a program will have two important prerequisites. To be eligible, applying institutions and individuals must have developed a research program with stated goals and objectives. Additionally, the institution must have a continuing commitment to the promotion of medical research.

It is envisioned that this will be a cooperative effort among the AOA, the specialty colleges, and individual institutions. Although there is a long way to go before these programs are established, the critical groundwork has been laid. Important policies have been formed that remove many of the obstacles that have previously prevented the integration of research in postdoctoral training. As a result, specialty colleges can develop guidelines that permit the creation of research-oriented training programs within the framework of the AOA approval process.

The Bureau of Research continues to explore other opportunities to stimulate the career develop- ment of D.O.s as clinical investigators. An important factor is the attitude of the osteopathic medical student doctor. The Bureau thinks that instillation of a research perspective on medicine in each student from the first day of medical school is critical. Students should be exposed to basic science and clinical research. They should understand that medicine has advanced because of the collaborative efforts of basic and clinical scientists. Today's students must understand that research is a key to the growth and advancement of osteopathic medicine.

A new program has been established by the $\mathrm{Bu}$ reau to stimulate the student doctor to explore in his or her own mind the scientific bases for osteopathic medicine. The Burnett Osteopathic Student Research Award will be given annually to an osteopathic medical student for the best scientific paper on a research proposal to study an aspect of osteopathic medical philosophy or practice. In developing their paper, students are encouraged to consult with their instructors. It is hoped that the exchange of ideas and the increased dialogue among faculty and students will heighten the presence of research in the medical school setting.

For those students and postdoctoral trainees who desire a valuable research experience, the Bureau continues to provide support. The Burroughs Wellcome Osteopathic Research Fellowship Program awards seven $\$ 5,000$ fellowships annually. Projects may take any of several forms, and fellows are encouraged to develop a project in collaboration with a faculty sponsor. After successful completion of one or two fellowship years, the investigators may seek funding of larger projects through the AOA research grant program. This path is viewed as one approach that physicians may take to develop their investigative skills.

\section{Comment}

It is clear that there is a great challenge before the osteopathic medical profession. Entering a second century, the profession is keenly aware that research is vital and that substantial effort is required. The AOA is making a commitment to research for the future. To succeed, however, requires the commitment of all parties - colleges of osteopathic medicine, osteopathic hospitals, specialty colleges of the AOA, and, most important, every D.O.

Dr. Rivers is assistant director, Research and Evaluation, AOA Department of Education, Chicago, Illinois. 
